OPEN ACCESS

Edited by:

Mark A. Elliott,

National University of Ireland Galway,

Ireland

Reviewed by:

Christine M. Falter

University of Cologne, Germany

Omar Mothersill,

National University of Ireland Galway, Ireland

*Correspondence: Yael Mazor

yael.mazor@gmail.com

Specialty section:

This article was submitted to

Psychopathology,

a section of the journal

Frontiers in Psychiatry

Received: 30 August 2016 Accepted: 05 December 2016

Published: 19 December 2016

Citation:

Mazor Y, Gelkopf M, Mueser KT and Roe D (2016) Posttraumatic Growth in Psychosis.

Front. Psychiatry 7:202. doi: 10.3389/fpsyt.2016.00202

\section{Posttraumatic Growth in Psychosis}

\author{
Yael Mazor ${ }^{1 *}$, Marc Gelkopf', Kim T. Mueser ${ }^{2}$ and David Roe ${ }^{1}$ \\ ${ }^{1}$ Faculty of Social Welfare and Health Sciences, Department of Community Mental Health, University of Haifa, Haifa, Israel, \\ ${ }^{2}$ Department of Occupational Therapy, Psychology, and Psychiatry, Boston University Center for Psychiatric Rehabilitation, \\ Boston, MA, USA
}

Objective: Recent research has shown high rates of exposure to trauma among people with serious mental illness (SMI). In addition, studies suggest that psychosis and mental illness-related experiences can be extremely traumatic. While some individuals develop full blown PTSD related to these experiences, it has been noted that some may also experience posttraumatic growth (PTG). However, few studies have examined PTG as a possible outcome in people who have experienced psychosis.

Method: To further understand the relationships between psychosis and PTG, 121 participants were recruited from community mental health rehabilitation centers and administered trauma and psychiatric questionnaires.

Results: High levels of traumatic exposure were found in the sample. Regarding our main focus of study, we observed that people who endured psychosis can experience PTG, and that PTG is mediated by meaning making and coping self-efficacy (CSE) appraisal. Psychotic symptoms were found to be a major obstacle to meaning making, CSE, and PTG, whereas negative symptoms were found to be significantly related to PTG when mediated by meaning making and CSE.

Conclusion: The current research provides preliminary evidence for potential role of meaning making and CSE as mediators of PTG in the clinical, highly traumatized population of people with SMl who have experienced psychosis. This may have both research as well as clinical practice relevance for the field of psychiatric rehabilitation.

Keywords: posttraumatic growth, psychosis, psychopathological symptoms, meaning making, coping selfefficacy

\section{INTRODUCTION}

Research has suggested that psychosis and mental illness-related experiences can be extremely traumatic (1-3). As in the case of traumatic life events in non-clinical populations (4), psychosis could theoretically also lead to posttraumatic growth (PTG). PTG consists of five facets of growth: appreciation of life, relating to others, new found possibilities in life (for example, a new career pursuit following trauma), personal strength, and spiritual change (5, 6). PTG occurs after a trauma, which may have significant negative impact, but at the same time be the starting point of an emotional and behavioral rebuilding process, through PTG (7). The promotion of PTG may contribute to the treatment of people who experienced massive traumas such as people with serious mental illness (SMI) who have endured psychotic symptoms. Although multiple studies have found that traumas are frequent and repetitive experiences in these individuals $(8,9)$, and qualitative studies on the experiences of recovery have reported elements of growth in this population $(10,11)$, only 
few have explored the possibility of PTG in people with SMI who have experienced psychosis.

Psychotic symptoms are a common feature of SMI, most prominent in schizophrenia, but frequently present in other disorders as well, such as bipolar disorder and major depression. Individuals who have experienced psychosis are also more likely to have been exposed to trauma (12) and are more vulnerable to developing posttraumatic symptomatology $(8,13-16)$. The impact of exposure to traumatic events has been found to worsen the characteristic symptoms of SMI, such as grandiose or paranoid delusions, hallucinations, anxiety, and depression and to contribute to general psychopathology (e.g., depression, anxiety, impaired social judgment, etc.) in psychiatric disorders such as cognitive deficits, risk taking behaviors, and the experience of psychosis itself $(8,17-20)$. A possible explanation to the adverse impact of traumatic exposure on SMI symptoms is the "social defeat hypothesis of Schizophrenia" (21). This approach suggests that long-term exposure to the experience of social defeat or exclusion can lead to the sensitization of the mesolimbic dopamine system, whereby exposure to a given stimulus (e.g., stressor), may result in an increased response to subsequent exposures. Continuous humiliation and seclusion, which are inherent in childhood traumas, such as abuse, can indeed result in feelings of social defeat, and therefore repeated traumatic exposure may be one of the reasons of the aggravation of SMI symptoms (12).

Psychopathological symptoms can appear in the form of both positive and negative symptoms. Positive (or psychotic) symptoms can be experienced as severely traumatic on account of reality distortions such as delusions and hallucinations (3, 22-25), and can contain adverse and frightening, and potentially traumatic content.

Negative symptoms could also contribute to the traumatic experiencing of psychosis. These symptoms manifest in a lack of energy, drive, and interest, which are caused by a basic inhibition in motivation (26-28). Amotivation is one of the negative symptom groups and is specifically relevant to the possible traumatic sequelae of psychosis. These include anhedonia, lack of social drive and social isolation, and treatment non-adherence $(8,29,30)$. This chain of events might elevate the risk for relapse and indirectly lead to traumatic experiences that are part of psychosis $(3,8)$.

Alongside, the adverse consequences of psychopathological symptoms are the unique outcome of coping with adversity (31), namely, PTG. PTG manifests itself after trauma through one's thought processes, emotions, and behaviors, and it may include both a constructive and an illusory aspect (32). PTG is facilitated by the reduction of emotional distress associated with traumatic experiences, which allows ruminations to transform into deliberate thinking about the trauma and its aftermath. As a result, people may feel that they have changed positively following their traumatic experience $(31,33)$. In addition, PTG can also express itself as concrete actions whereby people act in new and different ways in the face of trauma $(34,35)$. Although traumatic experiences are common in people who have experienced psychosis-studies have suggested that up to $98 \%$ of people who experienced psychosis were exposed to prior trauma (36), only a few studies investigated PTG in this population (37-39). Thus, we still lack the understanding of what might facilitate PTG in these individuals.

One important factor that may contribute to the development of PTG is coping self-efficacy (CSE), which has been found to be positively correlated with PTG (40). CSE is the perceived or appraised ability to manage one's personal functioning and environmental demands following traumatic or stressful events, through cognitive processes and changes in one's belief system $(41,42)$. These processes can provide a sense of control and actual control in the face of traumatic adversity, reducing vulnerability to being overwhelmed by helplessness $(42,43)$. CSE includes three dimensions: (a) self-appraisal of coping capabilities; (b) transformative actions [e.g., the ability to change or maintain one's coping style when faced with different challenges (43)]; and (c) thought control efficacy (i.e., the sense of control people have over their thoughts, and their ability not to be influenced continuously by cognitive intrusions). Research suggests that the ability to accept situations that cannot be changed is a major aspect in adaptation to uncontrollable events, and that the reappraisal of coping in a more positive light is one path to PTG $(32,44)$. An important question is whether individuals who experience psychosis and therefore might suffer from stereotyped thinking, delusions, preoccupation, and lack of insight, might be hampered in their ability to develop self-appraisals, transformative actions, and the belief in one's ability to control one's thoughts (i.e., CSE), and therefore possibly PTG.

Another major factor that is both protective and facilitative of PTG is meaning making. The need to search for meaning is a basic human tendency (45), which may be activated after the violation of basic life assumptions regarding oneself and the world following trauma (46-49). Definitions and measures of meaning making vary throughout theories (50); however, all theoreticians agree that meaning is a crucial component in confronting adversity and promoting growth (51). The inability to find meaning in life after encountering adverse situations can result in extreme distress (45). Studies show that individuals with SMI are capable of searching for and finding meaning (11, 52). For example, Piltch (53) described her recovery process from major depression, in which finding meaningful roles and activities (i.e., parenthood and acquiring a profession), was facilitative not only of recovery, but also had elements that can otherwise be described as PTG. However, as psychiatric symptoms may affect meaning making processes (54-56), we do not know if it affects PTG in individuals who have experienced psychosis. We therefore posed the question of whether PTG is contingent upon meaning making and CSE in people who experienced psychosis.

Trauma, although excruciating, may set in motion a process of rebuilding and positive change (i.e., PTG). However, yet to be thoroughly investigated is the possibility of PTG in individuals who experienced psychosis. To address this issue, we conducted a study to examine the extent to which PTG occurs and to assess the possible mediating effect of CSE and meaning making processes, in such individuals with SMI. We examined the relationships between positive psychotic symptoms, negative symptoms, general psychopathology, and PTG, and hypothesized that: 
(a) Positive psychotic symptoms (such as conceptual disorganization and suspicion/persecution), negative symptoms, and general symptoms will be negatively correlated with meaning making processes, CSE, and PTG.

(b) CSE and meaning making processes will be positively correlated with PTG and mediate the relationship between positive psychotic symptoms, negative symptoms, general psychopathological symptoms, and PTG in people who have experienced psychosis.

\section{MATERIALS AND METHODS}

\section{Participants}

One hundred and twenty-one participants were recruited from community mental health rehabilitation services of the Israeli Ministry of Health. To be eligible for the study, participants had to meet Israeli criteria for having a "psychiatric disability" severe enough to compromise at least $40 \%$ of one's functioning. This is determined by a committee, including a psychiatrist and recognized by National Insurance Institute regulations. The last registry hospital discharge diagnosis of schizophrenia, of whom all Israeli rehab service users are part of, has acceptable sensitivity and specificity assessed against research diagnosis (57); has acceptable stability over time (58); and captured over $90 \%$ of cases with schizophrenia disorders based on research criteria in a community sample (59). Inclusion criteria were: men and women over the age of 18 , who had been psychiatrically hospitalized in the past, had experienced psychotic symptoms according to their clinicians and corroborated by the Positive and Negative Syndrome Scale (PANSS) [(60) -see measures] clinical interview (administered by the first author) and were eligible to sign an informed consent.

Potential participants were referred to the study by mental health professionals in the rehabilitation services. Participants who wished to take part and met the inclusion criteria contacted the researcher and signed an informed consent form.

Participants completed the questionnaires and were administered the PANSS clinical interview, after which they were paid for their participation. Data were collected by the first author between May 2014 and October 2014. The study protocol was reviewed and approved by the University of Haifa ethics board.

\section{Measures}

\section{Demographic Data}

Factors such as gender, age, education, and marital status were queried.

\section{Clinical History}

Diagnosis and time since last hospitalization were determined by psychiatrists and other mental health professionals during the intake procedure.

\section{Traumatic History}

The Trauma History Screen [THS (61)] is an 18-item instrument used to screen lifetime trauma history. The THS examines high magnitude stressors (HMS), traumatic stressors (TS), and persisting posttraumatic distress, which refers to sudden events that have been found to cause extreme distress. Items include natural disasters, interpersonal traumas, military trauma, etc. For each potentially traumatic event on the scale, participants indicated whether they had ever experienced it in a binary (yes/no) format. The THS has been found to be reliable and have good psychometric properties (61). The THS was translated into Hebrew, back translated, with any language discrepancies resolved by a third bilingual person with trauma expertise. Three psychosis-related items were added, namely: "Have you ever experienced psychosis?" "Have you been psychiatrically hospitalized?" and "Do you suffer from serious mental illness?"

\section{Positive, Negative, and General Symptoms}

The PANSS (60) is a semi-formalized 30-item interview used to assess affective, motor, cognitive, perceptual, attentional, integrative, and interactive functions in individuals with SMI. The PANSS measures three domains: positive symptoms (7 items; e.g., hallucinations, delusions), negative symptoms (7 items; e.g., blunted affect, social withdrawal), and general symptoms (16 items; e.g., depression, anxiety). The symptoms are assessed on a 7-point scale that represents the severity of psychopathology from 1 (absent) to 7 (extreme). The summations of ratings range from 7 to 49 for the positive and negative scales and from 16 to 112 for the general symptoms scale. The reliability and validity of the PANSS in Hebrew are well established $(62,63)$. The internal consistency of the PANSS in the present sample was good $(\alpha=0.86)$. The PANSS interviews were administered by the first author, an experienced mental health professional, after extensive clinical training on the scale.

\section{Posttraumatic Growth Inventory (PTGI)}

The PTGI (5) is a 21-item scale that assesses positive changes occurring in response to major adversities. The PTGI is scored on a 6-point Likert scale, from 0 ("I did not experience this change as a result of my crisis") to 5 ("I experienced this change to a very great extent as a result of my crisis"). The Hebrew PTGI showed good psychometric properties $(64,65)$ and was successfully used in previous studies (66). Cronbach's $\alpha$ for the PTGI factors in the present sample was good to excellent (range $\alpha=0.84-0.92$ ). In the current research, one question was added in which participants were asked to name the traumatic event to which they referred regarding their PTG. PTG summation of ratings range from 0 to 105. A cutoff point regarding PTG level was determined as follow: scores of 45 and below represented none to low PTG levels, whereas scores of 46 and above represented medium to very high PTG levels.

\section{Coping Self-Efficacy}

The CSE Scale (67) is a 26-item scale that assesses the respondent's confidence in performing coping behaviors when faced with life challenges and is constructed from three facets: (a) problemfocused coping; (b) ability to stop unpleasant emotions and thoughts, and (c) ability to get support from family and friends. The CSE is scored on a 10-point scale from 0 ("cannot do it at 
all") to 10 ("certain I can do it when faced with challenges"). The CSE has been used in several studies worldwide $(68,69)$ and has been translated and back translated into Hebrew and English. The internal consistency of the CSE in the present study was excellent $(\alpha=0.93)$.

\section{Meaning in Life}

The Meaning in Life Questionnaire [MLQ (51)] is a 10-item scale that was used to identify meaning making processes; namely, the presence of meaning and the search for meaning, on a scale from1 ("absolutely untrue") to 7 ("absolutely true"). The MLQ was used in a variety of studies $(70,71)$ and was translated and back translated into Hebrew and English. Cronbach's $\alpha$ for the MLQ total score was excellent $(\alpha=0.90)$.

\section{Data Analyses}

The study hypotheses about mediation were examined regarding (a) PANSS positive, negative, and general symptoms as the independent variable (IV), meaning making processes (MLQ) and CSE as mediators, and post-traumatic growth inventory (PTGI) as the dependent variable (DV). Mediation was examined with Preacher and Hayes' $(72,73)$ bootstrapping procedures (MEDIATE, SPSS22.0). To avoid the inflation of alpha due to multiple analyses, the Bonferroni criterion was applied for each table, resulting in a cutoff of $p=0.008(0.05 / 6=0.008)$. Due to high inter-correlations between the MLQ factors $(r=0.59$, $p<0.001)$ and between the CSE factors $(r=0.62-0.80, p<0.001)$, total scores of MLQ and CSE factors were used. Due to moderate inter-correlations between the PANSS factors ( $r=0.53-0.65$, $p<0.001)$, the total score was used in the main analyses. For exploratory purposes, in the final part of the study, the three factors were used, each in a separate analysis. Moderate to high inter-correlations were found between the PTGI factors as well ( $r=0.30-0.67, p<0.001)$, but because this measure was the $\mathrm{DV}$, each factor was used separately. To understand the nature of marginal relationships found between MLQ and PANSS positive symptoms, the MLQ was split at the median and the PANSS positive symptom factor was split into three equal groups, which were analyzed using a chi-square test.

\section{RESULTS}

\section{Descriptive Information}

Table 1 summarizes the demographic, clinical, and trauma characteristics of the study sample. The participants were an average of 43.8-years old ( $\mathrm{SD}=11.8)$. Most of them had schizophrenia or schizoaffective disorder. Over half of the participants (57\%, based upon the traumatic history screen) had previous traumatic experiences; two thirds (66.2\%) reported events that caused extreme distress, and $47.1 \%$ of participants reported exposure to continuous TS. The most common HMS were psychiatric hospitalization (90.1\%) and psychotic symptoms (90.9\%).

\section{Correlational Analyses}

To assess the relationships between the study variables, Pearson correlations were performed, which are presented in Table 2.
TABLE 1 | Participants' demographic and clinical characteristics $(N=121)$.

\begin{tabular}{|c|c|c|}
\hline Variable & $n$ & $\%$ \\
\hline \multicolumn{3}{|l|}{ Gender } \\
\hline Male & 56 & 46.3 \\
\hline Female & 65 & 53.7 \\
\hline \multicolumn{3}{|l|}{ Diagnosis } \\
\hline Schizophrenia and schizoaffective & 95 & 78.5 \\
\hline Bipolar with past psychotic symptoms & 9 & 7.4 \\
\hline Personality or affective disorders with psychotic symptoms & 17 & 14.1 \\
\hline \multicolumn{3}{|l|}{ Family status } \\
\hline Single & 70 & 57.9 \\
\hline Divorced/separated/widowed & 32 & 26.5 \\
\hline Married/living in couple relationship & 19 & 15.6 \\
\hline \multicolumn{3}{|l|}{ Children } \\
\hline No children & 82 & 67.8 \\
\hline With children & 39 & 32.2 \\
\hline \multicolumn{3}{|l|}{ Housing status } \\
\hline Lives independently & 24 & 19.8 \\
\hline Lives with family & 37 & 30.6 \\
\hline Rehabilitation housing services in the community & 60 & 49.6 \\
\hline \multicolumn{3}{|l|}{ Employment status } \\
\hline Not working & 33 & 27.3 \\
\hline Working in community rehabilitation factories & 88 & 72.7 \\
\hline \multicolumn{3}{|l|}{ Psychiatric hospitalization } \\
\hline Were psychiatrically hospitalized & 119 & 98.3 \\
\hline No hospitalization & 2 & 1.7 \\
\hline \multicolumn{3}{|l|}{ Time since last psychiatric hospitalization } \\
\hline Less than 1 year & 15 & 12.4 \\
\hline $1-5$ years & 48 & 39.7 \\
\hline More than 5 years & 28 & 23.1 \\
\hline More than 10 years & 24 & 19.8 \\
\hline Did not answer & 6 & 5.0 \\
\hline \multicolumn{3}{|l|}{ Traumatic history (including multiple experiences) } \\
\hline Experienced more than five high magnitude stressors & 106 & 87.5 \\
\hline Experienced sexual abuse as a child & 31 & 25.6 \\
\hline Experienced violence as a child & 47 & 39.7 \\
\hline Experienced a sudden death/loss of a loved one & 81 & 66.9 \\
\hline
\end{tabular}

Higher PTG was generally related to lower PANSS scores and to higher meaning making and CSE scores. This was found for PTG total scores, as well as for most subscales, except for some of the relationships between PTG and PANSS positive symptoms. In addition, higher PANSS scores were related to lower meaning making and CSE scores, whereas higher meaning making and higher CSE were interrelated. An exception was the marginal correlation between meaning making and PANSS positive symptoms ( $p=0.076$; subsequent lowest $p$ value was.081). Correlations between age, years of education, time of hospitalization, and the total PTGI score were not significant, nor were gender differences on any of the measures. Family status had low variance; therefore, analyses were conducted without the control of background variables.

To understand the nature of the marginal relationship between meaning making (MLQ) and PANSS positive symptoms, MLQ was split at the median [at score 47 (range 10-70)] and PANSS positive symptoms were split into three equal groups [at scores 16 and 21 (range 9-32)] and analyzed 
TABLE 2 | Means, SDs, and correlations of the research variables, subscale scores $(N=121)$.

\begin{tabular}{|c|c|c|c|c|c|c|c|c|c|c|c|}
\hline Variable, M (SD) & $\begin{array}{l}\text { PTGI } \\
\text { relation } \\
\text { with } \\
\text { others }\end{array}$ & $\begin{array}{l}\text { PTGI new } \\
\text { possibilities }\end{array}$ & $\begin{array}{c}\text { PTGI } \\
\text { personal } \\
\text { strength }\end{array}$ & $\begin{array}{l}\text { PTGI spiritual } \\
\text { change }\end{array}$ & $\begin{array}{c}\text { PTGI } \\
\text { appreciation } \\
\text { of life }\end{array}$ & $\begin{array}{l}\text { PANSS } \\
\text { total }\end{array}$ & $\begin{array}{l}\text { PANSS positive } \\
\text { symptoms }\end{array}$ & $\begin{array}{l}\text { PANSS negative } \\
\text { symptoms }\end{array}$ & $\begin{array}{c}\text { PANSS } \\
\text { general } \\
\text { psychopathology }\end{array}$ & $\begin{array}{l}\text { Meaning total } \\
\text { (Meaning in Life } \\
\text { Questionnaire) }\end{array}$ & $\begin{array}{l}\text { Coping self-efficacy } \\
\text { (CSE) total }\end{array}$ \\
\hline $\begin{array}{l}\text { PTGl total score } \\
61.16(21.87)\end{array}$ & $0.89^{\star \star \star}$ & $0.86^{\star \star \star}$ & $0.81^{\star \star \star}$ & $0.62^{\star \star \star}$ & $0.78^{\star \star \star}$ & $-0.38^{\star \star \star}$ & $-0.20^{*}$ & $-0.38^{\star \star \star}$ & $-0.36^{\star \star \star}$ & $0.68^{\star \star \star}$ & $0.66^{\star \star \star}$ \\
\hline $\begin{array}{l}\text { PTGl relation with } \\
\text { others } \\
19.91 \text { (7.98) }\end{array}$ & & $0.67^{\star \star \star}$ & $0.64^{\star \star \star}$ & $0.49^{\star \star \star}$ & $0.61^{\star \star \star}$ & $-0.41^{\star \star \star}$ & $-0.26^{\star \star}$ & $-0.42^{\star \star \star}$ & $-0.34^{\star \star \star}$ & $0.58^{\star \star \star}$ & $0.56^{\star \star \star}$ \\
\hline $\begin{array}{l}\text { PTGI new } \\
\text { possibilities } \\
14.99(6.42)\end{array}$ & & & $0.60^{\star \star \star}$ & $0.48^{\star \star \star}$ & $0.61^{\star \star \star}$ & $-0.31^{\star \star *}$ & -0.15 & $-0.33^{\star \star \star}$ & $-0.28^{\star \star}$ & $0.61^{\star \star \star}$ & $0.62^{\star \star \star}$ \\
\hline $\begin{array}{l}\text { PTGI personal } \\
\text { strength } \\
12.45(4.58)\end{array}$ & & & & $0.40^{\star \star \star}$ & $0.65^{\star \star \star}$ & $-0.28^{\star \star}$ & -0.16 & $-0.20^{\star}$ & $-0.31^{\star \star \star}$ & $0.47^{\star \star \star}$ & $0.54^{\star \star \star}$ \\
\hline $\begin{array}{l}\text { PTGl spiritual } \\
\text { change } \\
4.86(3.41)\end{array}$ & & & & & $0.30^{\star \star \star}$ & $-0.21^{*}$ & -0.05 & $-0.24^{\star \star}$ & $-0.20^{\star}$ & $0.50^{\star \star \star}$ & $0.35^{\star \star}$ \\
\hline $\begin{array}{l}\text { PTGl appreciation } \\
\text { of life } 8.96(4.31)\end{array}$ & & & & & & $-0.28^{\star \star}$ & -0.12 & $-0.25^{\star \star}$ & $-0.29^{\star \star \star}$ & $0.55^{\star \star \star}$ & $0.54^{\star \star \star}$ \\
\hline $\begin{array}{l}\text { PANSS total } \\
84.20(19.33)\end{array}$ & & & & & & & $0.76^{\star \star \star}$ & $0.86^{\star \star \star}$ & $0.91^{\star \star \star}$ & $-0.39^{\star \star \star}$ & $-0.40^{\star \star \star}$ \\
\hline $\begin{array}{l}\text { PANSS positive } \\
\text { symptoms } \\
18.79(5.08)\end{array}$ & & & & & & & & $0.53^{\star \star \star}$ & $0.57^{\star \star \star}$ & -0.16 & $-0.21^{*}$ \\
\hline $\begin{array}{l}\text { PANSS negative } \\
\text { symptoms } \\
23.73(7.61)\end{array}$ & & & & & & & & & $0.65^{\star \star \star}$ & $-0.34^{\star \star \star}$ & $-0.31^{\star \star \star}$ \\
\hline $\begin{array}{l}\text { PANSS general } \\
\text { psychopathology } \\
41.68(9.76)\end{array}$ & & & & & & & & & & $-0.43^{\star \star \star}$ & $-0.45^{\star \star \star}$ \\
\hline $\begin{array}{l}\text { Meaning total } \\
\text { (MLQ) } 45.54 \\
\text { (14.57) }\end{array}$ & & & & & & & & & & & $0.74^{\star \star \star}$ \\
\hline $\begin{array}{l}\text { CSE total } \\
139.80(50.64)\end{array}$ & & & & & & & & & & & \\
\hline
\end{tabular}


TABLE 3 | Mediation analyses for Meaning in Life Questionnaire total, Positive and Negative Syndrome Scale total, and Posttraumatic Growth Inventory (total and its five dimensions) scores $(N=121)$.

\begin{tabular}{|c|c|c|c|c|c|c|}
\hline \multirow[t]{2}{*}{ Dependent variable (DV) } & \multirow[t]{2}{*}{ Independent variable (IV) } & \multirow[t]{2}{*}{ Mediator } & \multirow{2}{*}{$\begin{array}{c}\text { IV to mediator } \\
B \text { (SE) }\end{array}$} & \multirow{2}{*}{$\begin{array}{c}\text { Mediator to DV } \\
B \text { (SE) }\end{array}$} & \multirow{2}{*}{$\begin{array}{c}\text { Mediation effect } \\
B(\mathrm{SE})\end{array}$} & \multirow[t]{2}{*}{$z$} \\
\hline & & & & & & \\
\hline PTGl total & PANSS total & MLQ total & $-0.29^{\star \star \star}(0.06)$ & $0.93^{\star \star \star}(0.11)$ & $-0.27(0.07)$ & $4.02^{\star \star \star}$ \\
\hline PTGI relations with others total & & & & $0.09^{\star \star}(0.03)$ & $-0.08(0.02)$ & $3.60^{\star \star \star}$ \\
\hline PTGI new possibilities total & & & & $0.25^{\star \star \star}(0.03)$ & $-0.07(0.02)$ & $3.97^{\star \star \star}$ \\
\hline PTGI personal strength total & & & & $0.14^{\star \star \star}(0.03)$ & $-0.04(0.01)$ & $3.07^{\star \star}$ \\
\hline PTGI spiritual change total & & & & $0.12^{\star \star \star}(0.02)$ & $-0.03(0.01)$ & $3.89^{\star \star \star}$ \\
\hline PTGI appreciation of life total & & & & $0.15^{\star \star \star}(0.02)$ & $-0.05(0.01)$ & $3.40^{\star \star \star}$ \\
\hline
\end{tabular}

${ }^{* *} p<0.01,{ }^{* * *} p<0.001$.

TABLE 4 | Mediation analyses for Positive and Negative Syndrome Scale total, coping self-efficacy total, and Posttraumatic Growth Inventory (total and its five dimensions) scores $(N=121)$.

\begin{tabular}{|c|c|c|c|c|c|c|}
\hline \multirow[t]{2}{*}{ Dependent variable (DV) } & \multirow[t]{2}{*}{ Independent variable (IV) } & \multirow[t]{2}{*}{ Mediator } & \multirow{2}{*}{$\begin{array}{c}\text { IV to mediator } \\
B \text { (SE) }\end{array}$} & \multirow{2}{*}{$\begin{array}{c}\text { Mediator to DV } \\
B \text { (SE) }\end{array}$} & \multirow{2}{*}{$\begin{array}{c}\text { Mediation effect } \\
B(\mathrm{SE})\end{array}$} & \multirow[t]{2}{*}{$z$} \\
\hline & & & & & & \\
\hline PTGI total & PANSS total & CSE total & $-1.05^{\star \star \star}(0.22)$ & $0.26^{\star \star \star}(0.03)$ & $-0.27(0.08)$ & $3.53^{\star \star \star}$ \\
\hline PTGI relations with others total & & & & $0.07^{\star \star \star}(0.01)$ & $-0.08(0.02)$ & $3.33^{\star \star \star}$ \\
\hline PTGI new possibilities total & & & & $0.07^{\star \star \star}(0.01)$ & $-0.08(0.02)$ & $3.85^{\star \star \star}$ \\
\hline PTGI personal strength total & & & & $0.05^{\star \star \star}(0.01)$ & $-0.05(0.02)$ & $2.93^{\star \star}$ \\
\hline PTGI spiritual change total & & & & $0.02^{\star \star}(0.01)$ & $-0.02(0.01)$ & $2.88^{\star \star}$ \\
\hline PTGI appreciation of life total & & & & $0.04^{\star \star \star}(0.01)$ & $-0.05(0.02)$ & $2.83^{\star \star}$ \\
\hline
\end{tabular}

${ }^{* *} p<0.01,{ }^{* *} p<0.001$.

TABLE 5 | Mediation analyses for the dimensions of Positive and Negative Syndrome Scale, Meaning in Life Questionnaire total, coping self-efficacy total, and Posttraumatic Growth Inventory total $(N=121)$.

\begin{tabular}{|c|c|c|c|c|c|c|}
\hline \multirow[t]{2}{*}{ Dependent variable (DV) } & \multirow[t]{2}{*}{ Independent variable (IV) } & \multirow[t]{2}{*}{ Mediator } & \multirow{2}{*}{$\begin{array}{c}\text { IV to mediator } \\
B \text { (SE) }\end{array}$} & \multirow{2}{*}{$\begin{array}{c}\text { Mediator to DV } \\
B(\mathrm{SE})\end{array}$} & \multirow{2}{*}{$\begin{array}{c}\text { Mediation effect } \\
B(\mathrm{SE})\end{array}$} & \multirow[t]{2}{*}{$z$} \\
\hline & & & & & & \\
\hline \multirow[t]{6}{*}{ PTGI total } & PANSS positive symptoms total & MLQ total & $-0.46(0.26)$ & $0.99^{\star \star \star}(0.10)$ & $-0.46(0.27)$ & 1.71 \\
\hline & & CSE total & $-2.08(0.89)$ & $0.28^{\star \star *}(0.03)$ & $-0.58(0.28)$ & 2.09 \\
\hline & PANSS negative symptoms total & MLQ total & $-0.64^{\star \star \star}(0.17)$ & $0.93^{\star \star \star}(0.11)$ & $-0.60(0.17)$ & $3.62^{\star \star \star}$ \\
\hline & & CSE total & $-2.06^{\star \star \star}(0.58)$ & $0.26^{\star \star \star}(0.03)$ & $-0.53(0.17)$ & $3.13^{\star \star}$ \\
\hline & PANSS general psychopathology total & MLQ total & $-0.64^{\star \star \star}(0.12)$ & $0.96^{\star \star \star}(0.11)$ & $-0.61(0.13)$ & $4.77^{\star \star \star}$ \\
\hline & & CSE total & $-2.32^{\star \star \star}(0.43)$ & $0.27^{\star \star \star}(0.03)$ & $-0.62(0.15)$ & $4.08^{\star \star \star}$ \\
\hline
\end{tabular}

${ }^{* *} p<0.01,{ }^{* * *} p<0.001$.

using a chi-square test. Results showed that among those with low positive symptoms, $62 \%$ reported high MLQ, whereas among those with high positive symptoms, only $29 \%$ reported high MLQ. Among those with moderate positive symptoms, $55 \%$ reported high MLQ $\left[\chi^{2}(2)=9.17\right.$, Cramer's $V=0.275$, $p=0.010]$.

To explore which positive symptoms were most strongly related to PTG, we computed the correlation between the severity of positive PANSS items and the MLQ. Conceptual disorganization (PANSS positive, item \#2) was negatively correlated to meaning in life $\left(r_{\rho}=-0.26, p=0.004\right)$ (i.e., higher conceptual disorganization was related to lower MLQ). Moreover, suspicion/ persecution (PANSS positive, item \#6) was negatively related to MLQ $\left(r_{\rho}=-0.18, p=0.05\right)$, whereas grandiosity (PANSS positive, item \#5) was positively related to MLQ $\left(r_{\rho}=0.18, p=0.04\right)$. The other correlations between the individual positive symptoms and MLQ total score were not significant.

\section{Mediation Analyses}

To assess the mediating role of meaning in life (MLQ) and CSE between the PANSS (IV) and PTGI (DV), mediation bootstrapping procedures were used, as mentioned above in the analytical strategy section. As the inter-correlations between the dimensions of PANSS were high $(r=0.53-0.65, p<0.001)$, we first assessed the mediated relationships with the five PTGI dimensions as the outcomes, and the PANSS total score as the IV. That is to say, mediation was examined for (a) PANSS total score, MLQ total score, and PTGI and its dimensions (Table 3), and (b) PANSS total score, CSE total score, and PTGI and its dimensions (Table 4). Due to the theoretical importance of PANSS dimensions, they were examined separately, with MLQ total score and CSE total score. This time, only the PTGI total score was used to avoid redundancy (Table 5).

Results of the role of MLQ regarding the relationship between PANSS total and PTGI total and its dimensions showed that MLQ 
mediated the relationship between the PANSS total score and the PTGI total score and its dimensions. In other words, less severe symptoms on the PANSS were associated with higher meaning making (MLQ total score), which in turn were related to a higher PTG on the PTGI.

Results regarding the mediating role of CSE total on PANSS total and PTGI total and dimensions showed that more severe symptoms on the PANSS were related to lower CSE on the CSE, which in turn were related to a lower level of PTG.

Finally, results showed that both MLQ and CSE mediated the relationship between PANSS negative symptoms and PANSS general psychopathology, and PTGI (see Table 5). Results also showed that lower scores on PANSS negative symptoms and PANSS general symptoms were related to higher MLQ scores and higher CSE scores, which were then related to higher PTGI total scores. However, mediation was not significant for PANSS positive symptoms and PTGI total score.

\section{DISCUSSION}

In the current study, $80 \%$ of participants indicated medium to very high levels of PTG. The mean score on overall PTG was moderately high $(\mathrm{M}=63)$, which is consistent with PTG scores in other populations such as earthquake survivors (74), bereaved parents (75), and women with breast cancer (76). Greater severity across all symptoms (positive, negative, and general psychopathological symptoms) was associated with worse CSE, less meaning making, and less PTG. One possible explanation for these associations may be that distress and distraction, which is associated with the above said symptoms, can thwart coping efforts and the ability to develop meaning from experiences, thus hamper PTG. Further findings, consistent with our hypotheses, indicated that CSE and meaning mediated the adverse impact of negative symptoms and general symptoms on PTG among people with SMI who have experienced psychosis. In addition, screening for traumatic history elicited elevated levels of traumatic exposure and cumulative trauma; $87.5 \%$ indicated experiencing more than five HMS during their lives, $25.6 \%$ experienced sexual abuse as children, and $39.7 \%$ experienced violence as children. These elevated levels of traumatic exposure replicate previous research suggesting high levels of trauma exposure in SMI $(9,77,78)$.

As hypothesized, positive symptoms had a significant negative relationship with CSE and PTG. This may be explained by the cognitive impairments that often accompany psychotic symptoms (79), which might be caused by aberrant assignment of salience to external objects and internal representations (54, 80-82). Indeed, reality distortions and conceptual disorganization might hamper cognitive processing (e.g., thoughtful reflection and awareness) and cause higher levels of distress alongside distressing reappraisal processes, which might lead to the development of less effective coping means (50,83-85). The accompanying distress might also elevate the feelings of uncontrollability and arousal that are inherent to psychotic symptoms (86-88), and further affect the appraisal of coping efficacy, actual coping (42, 89, 90), and possibly PTG. Another possible explanation for the negative relationship between positive symptoms, CSE and PTG, can stem from a neurocognitive perspective regarding deficits in executive function, which lead to passive avoidant coping strategies $(89,91)$ and can thus hamper both CSE and PTG. Finally, dopaminergic transmission dysfunction in the prefrontal cortex in schizophrenia and its grave effect on cognitive impairments (such as difficulties in working memory and decision making) (80), may also contribute to poor CSE appraisal and difficulties in experiencing PTG.

As hypothesized, positive symptoms had a significant negative relationship with meaning. This is consistent with previous studies reporting maladaptive processes of misplaced meaning and inaccurate interpretation of external and internal stimulus in psychosis $(92,93)$. Positive symptoms such as reality distortion and conceptual disorganization could hamper normal emotional processes that allow people to find meaning following adversity. Normal emotional processing is composed, in part, of self-regulation of emotional disturbances (e.g., anxiety, depression, etc.). When hampered, difficulties in meaning making might develop and subsequently hinder PTG. As witnessed by the negative correlation found between conceptual disorganization and meaning making, cognitive disorganization (as manifested by confusion, distress, and elevated levels of emotional stress reactivity) might also affect the emotional and cognitive ability to engage in meaning making (54-56). However, one positive symptom was found to have positive relationship with meaning (i.e., grandiosity; PANSS positive, item \#5). This raises two possibilities. First, high levels of grandiosity, such as the belief that one has special powers or abilities, or is famous or very accomplished, may be associated with a sense of discovery and relief that incorporates meaning and the experience of PTG, irrespective of the reality of those beliefs, reflecting the possible illusory part of PTG. The illusory part of PTG may thus be conceptualized as a component of PTG that helps people counterbalance their emotional distress in the face of trauma (32). Alternatively, high levels of grandiosity may merely reflect the psychotic symptoms these people still experience and not PTG.

The results of this study offer support for our hypothesis that negative symptoms and general psychopathological symptoms are negatively correlated with meaning, CSE, and PTG. The relationship between negative symptoms and meaning making may be explained by deficits inherent in negative symptoms, such as lack of motivation (28), over estimation of effort required to achieve goals, and the anticipation of negative outcomes (94, 95). These deficits, in turn, might lead to a lack in drive and energy to commence meaning making processes and thus might hamper PTG. Next, consistent with the literature $(90,96)$ and as mentioned above, higher levels of negative symptoms were linked to lower CSE levels. This might be because individuals with psychotic disorders have difficulty in anticipating pleasure (97, 98). This deficit in anticipatory pleasure might hamper people's ability to motivate themselves toward beneficial coping actions, thereby hampering CSE. This is in line with studies showing that people with psychosis perceive threats as less controllable, and that higher levels of negative as well as positive symptoms are linked to more dysfunctional coping strategies $(86,99,100)$, which might hinder PTG. Additionally, the negative correlations found between general psychopathological symptoms and 
meaning making, CSE and PTG, are in accordance with studies that found that higher levels of symptoms were related to higher distress levels, which could hinder the ability to appraise coping abilities and find meaning in people who experienced psychosis (90, 101, 102), and therefore impede PTG.

Finally, our findings offer support for the hypothesis that CSE and meaning making mediate the adverse impact of negative symptoms and general symptoms on PTG among people who have experienced psychosis. This is consistent with PTG literature, which suggests that a certain level of distress (which might be caused by both negative as well as general psychopathological symptoms, as mentioned above) is needed to embark on the journey of meaning making and PTG (31). On the other hand, this may not be the case when extreme or persistent levels of distress are evident, as might be seen in our findings regarding positive symptoms, namely that meaning making and CSE did not mediate the adverse impact of positive symptoms on PTG. This might be due to the potentially adverse consequences of positive symptoms on cognitive and emotional processes $(3,36$, 82), which could hamper meaning making, CSE, and ultimately PTG. In addition, the lack of mediation effect may be due to differences among participants regarding when psychotic symptoms were experienced (i.e., currently or in the past), thus effecting the ability to experience PTG.

A number of practice and policy-related implications can be drawn from the current study, including the importance of addressing traumatic exposure phenomena in rehabilitation programs for people with SMI who have experienced psychosis. Indeed, there is a lack of knowledge and treatment for individuals with SMI who also suffer from high levels of trauma exposure accompanied with a potential for re-traumatization due to psychosis itself. Considering the high levels of comorbidity found in this population extant, psychiatric interventions are not adequate for the treatment of the traumatic aspects of their illnesses. On the other hand, our findings suggest that even when facing high levels of symptoms individuals with SMI can experience PTG, contingent upon their ability to engage in meaning making processes and positively appraise their coping abilities. Hence, we suggest that greater emphasis should be placed on teaching these individuals more effective coping strategies, along with both broadening the perspective of recovery in mental health rehabilitation to PTG, and developing interventions promoting meaning making.

Although the current study has a number of strengths, including well-established assessment tools and a good sample size, it has some limitations. First, external validity might be limited due to the selection process. Indeed, participation was voluntary and participants were solely from rehabilitation centers in the community, which might both bias and limit the generalizability of our sample. Second, this study was cross-sectional and thus does not allow tracking of PTG development over time. We therefore recommend recruiting a large sample for longitudinal studies in the field of psychosis and PTG, specifically regarding the dynamics of positive psychotic symptoms and PTG. Finally, since the current study is exploratory in nature, the findings provide only preliminary data regarding mediational effects and further study of longitudinal data is needed to confirm it.

\section{ETHICS STATEMENT}

The study protocol was reviewed and approved by the University of Haifa ethics board. One hundred and twenty-one participants were recruited from community mental health rehabilitation services of the Israeli Ministry of Health (MOH). To be eligible for the study, participants had to meet Israeli criteria for having a "psychiatric disability" severe enough to compromise at least $40 \%$ of one's functioning. This is determined by a committee, including a psychiatrist, and recognized by National Insurance Institute regulations. The last registry hospital discharge diagnosis of schizophrenia, of whom all Israeli rehab service users are part of, has acceptable sensitivity and specificity assessed against research diagnosis (57); has acceptable stability over time (58); and captured over $90 \%$ of cases with schizophrenia disorders based on research criteria in a community sample (59). Inclusion criteria were: men and women over the age of 18 , who had been psychiatrically hospitalized in the past, had experienced psychotic symptoms according to their clinicians and corroborated by the PANSS [(60), see measures] clinical interview (administered by the first author), and were eligible to sign an informed consent. Potential participants were referred to the study by mental health professionals in the rehabilitation services. Participants who wished to take part and met the inclusion criteria contacted the researcher, and signed an informed consent form. Participants completed the questionnaires and were administered the PANSS clinical interview, after which they were paid for their participation. Data were collected by the first author between May 2014 and October 2014. The study protocol was reviewed and approved by the University of Haifa ethics board. Additional considerations: persons with severe mental illness.

\section{AUTHORS NOTE}

This paper is part of the first author's requirements to attain a Ph.D. degree.

\section{AUTHOR CONTRIBUTIONS}

YM: head researcher; substantial contributor to the conception and design of the work; responsible for the acquisition, analysis, and interpretation of data; revising the work critically for important intellectual content; approved final version for publication; agreeing to be accountable for all aspects of the work. MG: advisor; substantial contributor to the conception and design of the work; responsible for the analysis and interpretation of data; drafting and revising the work critically for important intellectual content; approved final version for publication; agreeing to be accountable for all aspects of the work. KM: substantial contributor to the conception and design of the work; responsible for the analysis and interpretation of data; revising the work critically for important intellectual content; approved final version for publication; agreeing to be accountable for all aspects of the work. DR: advisor; substantial contributor to the conception and design of the work; responsible for the analysis and interpretation of data; drafting and revising the 
work critically for important intellectual content; approved final version for publication; agreeing to be accountable for all aspects of the work.

\section{ACKNOWLEDGMENTS}

The authors thank the Laszlo N. Tauber Foundation for its generous scholarship support. The authors also thank to "Shekulo

\section{REFERENCES}

1. Berry K, Ford S, Jellicoe-Jones L, Haddock G. PTSD symptoms associated with the experience of psychosis and hospitalization: review of literature. Clin Psychol Rev (2013) 33:526-38. doi:10.1016/j.cpr.2013.01.011

2. Gelkopf M, Roe D, Werbloff N, Ohayon Hasson I, Mueser K, Caspi A, et al. The prevalence of full and partial PTSD among people with severe mental illness in Israel. J Nerv Ment Dis (2013) 201:244-50. doi:10.1097/ NMD.0b013e3182848d1e

3. Mueser KT, Lu W, Rosenberg SD, Wolfe R. The trauma of psychosis: posttraumatic stress disorder and recent onset psychosis. Schizophr Res (2010) 116:217-27. doi:10.1016/j.schres.2009.10.025

4. Pooley JA, Cohen L, O’Connor M, Taylor M. Posttraumatic stress and posttraumatic growth and their relationship to coping and self-efficacy in Northwest Australian cyclone communities. Psychol Trauma (2013) 5(4):392. doi:10.1037/a0028046

5. Tedeschi RG, Calhoun LG. The posttraumatic growth inventory: measuring the positive legacy of trauma. J Trauma Stress (1996) 9:455-71. doi:10.1007/ BF02103658

6. Tedeschi RG, Calhoun LG. Posttraumatic growth: conceptual foundations and empirical evidence. Psychol Inq (2004) 15:1-18. doi:10.1207/ s15327965pli1501_01

7. Calhoun LG, Tedeschi RG. The foundations of posttraumatic growth: new considerations. Psychol Inq (2004) 15:93-102. doi:10.1207/s15327965 pli1501_03

8. Mueser KT, Rosenberg SD, Goodman LA, Trumbetta SL. Trauma, PTSD, and the course of severe mental illness: an interactive model. Schizophr Res (2002) 53:123-43. doi:10.1016/S0920-9964(01)00173-6

9. Mueser KT, Salyers MP, Rosenberg SD, Goodman LA, Essock SM, Osher FC, et al. Interpersonal trauma and posttraumatic stress disorder in patients with severe mental illness: demographic, clinical, and health correlates. Schizophr Bull (2004) 30:45-57. doi:10.1093/oxfordjournals.schbul.a007067

10. Davidson L, Borg M, Marin I, Topor A, Mezzina R, Sells D. Processes of recovery in serious mental illness: findings from a multinational study. Am J Psychiatr Rehabil (2005) 8(3):177-201. doi:10.1080/15487760500339360

11. Roe D, Chopra M. Beyond coping with serious mental illness: toward personal growth. Am JOrthopsychiatry (2003) 73:334-44. doi:10.1037/0002-9432.73.3.334

12. Selten JP, van der Ven E, Rutten BP, Cantor-Graae E. The social defeat hypothesis of schizophrenia: an update. Schizophr Bull (2013) 39(6):1180-6. doi:10.1093/schbul/sbt134

13. Bendall S, McGorry P, Krstev H. The trauma of being psychotic. In: Larkin W, Morrison AP, editors. Trauma and Psychosis: New Directions for Theory and Therapy. East Sussex: Routledge (2006). p. 58-74.

14. Morrison A, Read J, Turkington D. Trauma and psychosis: theoretical and clinicalimplications. Acta Psychiatr Scand (2005) 112(5):327-9. doi:10.1111/j.1600-0447.2005.00644.x

15. Priebe S, Broker M, Gunkel S. Involuntary admission and posttraumatic stress disorder symptoms in schizophrenia patients. Compr Psychiatry (1998) 39:220-4. doi:10.1016/S0010-440X(98)90064-5

16. Shelvin M, Houston JE, Dorahy MJ, Adamson G. Cumulative traumas and psychosis: an analysis of the national comorbidity survey and the British psychiatric morbidity survey. Schizophr Bull (2008) 34:193-9. doi:10.1093/ schbul/sbm069

17. Goodman LA, Rosenberg SD, Mueser KT, et al. Physical and sexual assault history in women with serious mental illness: prevalence, correlates,
Tov" rehabilitation organization and "Consumers as providers" organization for their assistance in recruiting participants.

\section{SUPPLEMENTARY MATERIAL}

The Supplementary Material for this article can be found online at http://journal.frontiersin.org/article/10.3389/fpsyt.2016.00202/ full\#supplementary-material.

treatment, and future research directions. Schizophr Bull (1997) 23:685-96. doi:10.1093/schbul/23.4.685

18. Kilcommons A, Morrison AP. Relationships between trauma and psychosis: an exploration of cognitive and dissociative factors. Acta Psychiatr Scand (2005) 112:351-9. doi:10.1111/j.1600-0447.2005.00623.x

19. Penn DL, Corrigan PW, Bentall RP, Racenstein JM, Newman L. Social cognition in schizophrenia. Psychol Bull (1997) 121:114-32. doi:10.1037/0033-2909.121.1.114

20. Sherrer $M$. The role of cognitive appraisal in adaptation to traumatic stress in adults with serious mental illness: a critical review. Trauma Violence Abuse (2011) 12:151-67. doi:10.1177/1524838011404254

21. Selten JP, Cantor-Graae E. Hypothesis: social defeat is a risk factor for schizophrenia? Br J Psychiatry Suppl (2007) 51():s9-12. doi:10.1192/bjp.191.51.s9

22. American Psychiatric Association, Task Force on DSM-IV. Diagnostic and Statistical Manual of Mental Disorders: DSM-IV. Washington, DC: American Psychiatric Pub Inc. (1994).

23. American Psychiatric Association. DSM 5. Arlington, VA: American Psychiatric Association (2013).

24. Freeman D, Fowler D. Routes to psychotic symptoms: trauma, anxiety and psychosis-like experiences. Psychiatry Res (2009) 169(2):107-12. doi:10.1016/j.psychres.2008.07.009

25. Lysaker PH, LaRocco VA. The prevalence and correlates of trauma-related symptoms in schizophrenia spectrum disorder. Compr Psychiatry (2008) 49(4):330-4. doi:10.1016/j.comppsych.2007.12.003

26. Bleuler E. Dementia Praecox or the Group of Schizophrenias. Oxford, England: International Universities Press (1950).

27. Heerey EA, Gold JM. Patients with schizophrenia demonstrate dissociation between affective experience and motivated behavior. J Abnorm Psychol (2007) 116:268-78. doi:10.1037/0021-843X.116.2.268

28. Myin-Germeys I, Oorschot M, Collip D, Lataster J, Delespaul P, van Os J. Experience sampling research in psychopathology: opening the black box of daily life. Psychol Med (2009) 39:1533-47. doi:10.1017/S0033291708004947

29. Fervaha G, Foussias G, Agid O, Remington G. Impact of primary negative symptoms on functional outcomes in schizophrenia. Eur Psychiatry (2014) 29(7):449-55. doi:10.1016/j.eurpsy.2014.01.007

30. Foussias G, Remington G. Negative symptoms in schizophrenia: avolition and Occam's razor. Schizophr Bull (2010) 36:359-69. doi:10.1093/schbul/ sbn094

31. Tedeschi RG, Calhoun LG. Trauma \& Transformation: Growing in the Aftermath of Suffering. Thousand Oaks, CA: SAGE (1995).

32. Zoellner T, Maercker A. Posttraumatic growth in clinical psychology - a critical review and introduction of a two component model. Clin Psychol Rev (2006) 26(5):626-53. doi:10.1016/j.cpr.2006.01.008

33. Tedeschi RG, Calhoun LG, Cann A. Evaluating resource gain: understanding and misunderstanding posttraumatic growth. Appl Psychol (2007) 56:396-340. doi:10.1111/j.1464-0597.2007.00299.x

34. Hobfoll SE, Canetti-Nisim D, Johnson RJ. Exposure to terrorism, stress-related mental health symptoms, and defensive coping among Jews and Arabs in Israel. J Consult Clin Psychol (2006) 74:207-18. doi:10.1037/0022-006X.74.2.207

35. Hobfoll SE, Tracy M, Galea S. The impact of resource loss and traumatic growth on probable PTSD and depression following terrorist attacks. J Trauma Stress (2006) 19:867-78. doi:10.1002/jts.20166

36. Mueser KT, Trumbetta SL, Rosenberg SD, Vidaver R, Goodman LB, Osher FC, et al. Trauma and posttraumatic stress disorder in severe mental illness. J Consult Clin Psychol (1998) 66:493-9. doi:10.1037/0022-006X. 66.3.493 
37. Dunkley JE, Bates GW. Recovery and adaptation after first-episode psychosis: the relevance of posttraumatic growth. Psychosis (2015) 7(2):130-40. doi:10.1080/17522439.2014.936027

38. Mapplebeck C, Joseph S, Sabin-Farrell R. An interpretative phenomenological analysis of posttraumatic growth in people with psychosis. J Loss Trauma (2015) 20(1):34-45. doi:10.1080/15325024.2013.821375

39. Pietruch M, Jobson L. Posttraumatic growth and recovery in people with first episode psychosis: an investigation into the role of self-disclosure. Psychosis (2012) 4(3):213-23. doi:10.1080/17522439.2011.608434

40. Cieslak R, Benight C, Schmidt N, Luszczynska A, Curtin E, Clark RA, et al. Predicting posttraumatic growth among Hurricane Katrina survivors living with HIV: the role of self-efficacy, social support, and PTSD symptoms. Anxiety Stress Coping (2009) 22(4):449-63. doi:10.1080/10615800802403815

41. Bandura A. Self-efficacy: toward a unifying theory of behavioral change. Psychol Rev (1977) 84:191. doi:10.1037/0033-295X.84.2.191

42. Bandura A. On the functional properties of perceived self-efficacy revisited. J Manag (2012) 38:9-44. doi:10.1177/0149206311410606

43. Benight CC, Bandura A. Social cognitive theory of posttraumatic recovery: the role of perceived self-efficacy. Behav Res Ther (2004) 42:1129-48. doi:10.1016/j.brat.2003.08.008

44. Prati G, Pietrantoni L. Optimism, social support, and coping strategies as factors contributing to posttraumatic growth: a meta-analysis. J Loss Trauma (2009) 14(5):364-88. doi:10.1080/15325020902724271

45. Frankl VE. Man's Search for Meaning: An Introduction to Logotherapy. Tel-Aviv: Dvir Publishing House (1963/1970).

46. Herman JL. Trauma and Recovery. Tel-Aviv: Basic Books (1992).

47. Janoff-Bulman R. Shattered Assumptions: Towards a New Psychology of Trauma. New York: Free Press (1992).

48. Neimeyer RA. Meaning Reconstruction \& the Experience of Loss. Washington, DC: American Psychological Association (2001).

49. UpdegraffJA, Silver RC, Holman EA. Searching for and finding meaning in collective trauma: results from a national longitudinal study of the $9 / 11$ terrorist attacks. J Pers Soc Psychol (2008) 95:709-22. doi:10.1037/0022-3514.95.3.709

50. Park CL. Making sense of the meaning literature: an integrative review of meaning making and its effects on adjustment to stressful life events. Psychol Bull (2010) 136:257-301. doi:10.1037/a0018301

51. Steger MF, Frazier P, Oishi S, Kaler M. The meaning in life questionnaire: assessing the presence of and search for meaning in life. J Couns Psychol (2006) 53:80-93. doi:10.1037/0022-0167.53.1.80

52. Stolovy T, Lev-Wiesel R, Doron A, Gelkopf M. Meaning of life inside the psychiatric hospital: an exploratory study. J Nerv Ment Dis (2009) 197:133-5. doi:10.1097/NMD.0b013e3181963ede

53. Piltch CA. The role of self-determination in mental health recovery. Psychiatr Rehabil J (2016) 39(1):77. doi:10.1037/prj0000176

54. Lataster T, Valmaggia L, Lardinois M, van Os J, Myin-Germeys I. Increased stress reactivity: a mechanism specifically associated with the positive symptoms of psychotic disorder. Psychol Med (2013) 43(07):1389-400. doi:10.1017/S0033291712002279

55. Myin-Germeys I, van Os J, Schwartz JE, Stone AA, Delespaul PA. Emotional reactivity to daily life stress in psychosis. Arch Gen Psychiatry (2001) 58(12):1137-44. doi:10.1001/archpsyc.58.12.1137

56. Myin-Germeys I, Nicolson NA, Delespaul PA. The context of delusional experiences in the daily life of patients with schizophrenia. Psychol Med (2001) 31(03):489-98. doi:10.1017/S0033291701003646

57. Weiser M, Kanyas K, Malaspina D, Harvey PD, Glick I, Goetz D, et al. Sensitivity of ICD-10 diagnosis of psychotic disorders in the Israeli National Hospitalization Registry compared with RDC diagnoses based on SADS-L. Compr Psychiatry (2005) 46(1):38-42. doi:10.1016/j.comppsych.2004.07.016

58. Rabinowitz J, Slyuzberg M, Ritsner M, Mark M, Popper M, Ginath Y. Changes in diagnosis in a 9-year national longitudinal sample. Compr Psychiatry (1994) 35(5):361-5. doi:10.1016/0010-440X(94)90276-3

59. Weiser M, Werbeloff N, Dohrenwend BP, Levav I, Yoffe R, Davidson M. Do psychiatric registries include all persons with schizophrenia in the general population? A population-based longitudinal study. Schizophr Res (2012) 135(1):187-91. doi:10.1016/j.schres.2011.12.023

60. Kay SR, Fiszbein A, Opler LA. The positive and negative syndrome scale (PANSS) for schizophrenia. Schizophr Bull (1987) 13:261-76. doi:10.1093/ schbul/13.2.261
61. Carlson EB, Smith SR, Palmieri PA, Dalenberg C, Ruzek JI, Kimerling R, et al. Development and validation of a brief self-report measure of trauma exposure: the Trauma History Screen. Psychol Assess (2011) 23:463-77. doi:10.1037/a0022294

62. Barak Y, Shamir E, Weizman R. Would a switch from typical antipsychotics to risperidone be beneficial for elderly schizophrenic patients? A naturalistic, long-term, retrospective, comparative study. J Clin Psychopharmacol (2002) 22:115-20. doi:10.1097/00004714-200204000-00003

63. Werner P, Aviv A, Barak Y. Self-stigma, self-esteem and age in persons with schizophrenia. Int Psychogeriatr (2008) 20(01):174-87. doi:10.1017/ S1041610207005340

64. Laufer A, Solomon Z. Posttraumatic symptoms and posttraumatic growth among Israeli youth exposed to terror incidents. J Soc Clin Psychol (2006) 25:429-48. doi:10.1521/jscp.2006.25.4.429

65. Solomon Z, Laufer A. In the shadow of terror: changes in world assumptions in Israeli youth. J Aggress Maltreat Trauma (2005) 9:353-64. doi:10.1300/ J146v09n03_06

66. Levine SZ, Laufer A, Hamama-Raz Y, Stein E, Solomon Z. Posttraumatic growth in adolescence: examining its components and relationship with PTSD. J Trauma Stress (2008) 21:492-6. doi:10.1002/jts.20361

67. Chesney MA, Neilands TB, Chambers DB, Taylor JM, Folkman S. A validity and reliability study of the coping self-efficacy scale. Br J Health Psychol (2006) 11:421-37. doi:10.1348/135910705X53155

68. Carrico AW, Chesney MA, Johnson MO, Morin SF, Neilands TB, Remien RH, et al. Randomized controlled trial of a cognitive-behavioral intervention for HIV-positive persons: an investigation of treatment effects on psychosocial adjustment. AIDS Behav (2009) 13(3):555-63. doi:10.1007/ s10461-008-9429-6

69. Rodkjaer L, Chesney MA, Lomborg K, Ostergaard L, Laursen T, Sodemann M. HIV-infected individuals with high coping self-efficacy are less likely to report depressive symptoms: a cross-sectional study from Denmark. Int J Infect Dis (2014) 22:67-72. doi:10.1016/j.ijid.2013.12.008

70. Steger MF, Kashdan TB. Stability and specificity of meaning in life and life satisfaction over one year. J Happiness Stud (2007) 8(2):161-79. doi:10.1007/ s10902-006-9011-8

71. Steger MF, Owens GP, Park CL. Violations of war: testing the meaning-making model among Vietnam veterans. JClin Psychol (2015) 71(1):105-16. doi: $10.1002 /$ jclp. 22121

72. Preacher KJ, Hayes AF. SPSS and SAS procedures for estimating indirect effects in simple mediation models. Behav Res Methods Instrum Comput (2004) 36(4):717-31. doi:10.3758/BF03206553

73. Preacher KJ, Hayes AF. Asymptotic and resampling strategies for assessing and comparing indirect effects in multiple mediator models. Behav Res Methods (2008) 40(3):879-91. doi:10.3758/BRM.40.3.879

74. Chen J, Zhou X, Zeng M, Wu X. Post-traumatic stress symptoms and post traumatic growth: evidence from a longitudinal study following an earthquake disaster. PLoS One (2015) 10(6):e0127241. doi:10.1371/journal. pone. 0127241

75. Polatinsky S, Esprey Y. An assessment of gender differences in the perception of benefit resulting from the loss of a child. J Trauma Stress (2000) 13:709-18. doi:10.1023/A:1007870419116

76. Weiss T. Posttraumatic growth in women with breast cancer and their husbands: an intersubjective validation study. J Psychosoc Oncol (2002) 20:65-80. doi:10.1300/J077v20n02_04

77. Lu W, Yanos PT, Silverstein SM, Mueser KT, Rosenberg SD, Gottlieb JD, et al. Public mental health clients with severe mental illness and probable posttraumatic stress disorder: trauma exposure and correlates of symptom severity. J Trauma Stress (2013) 26(2):266-73. doi:10.1002/ jts.21791

78. Shaw K, McFarlane AC, Bookless C, Air T. The aetiology of postpsychotic posttraumatic stress disorder following a psychotic episode. J Trauma Stress (2002) 15:39-47. doi:10.1023/A:1014331211311

79. Keefe RS, Fenton WS. How should DSM-V criteria for schizophrenia include cognitive impairment? Schizophr Bull (2007) 33(4):912-20. doi:10.1093/ schbul/sbm046

80. Howes OD, Kapur S. The dopamine hypothesis of schizophrenia: version III-the final common pathway. Schizophr Bull (2009) 35(3):549-62. doi:10.1093/schbul/sbp006 
81. Kapur S. Psychosis as a state of aberrant salience: a framework linking biology, phenomenology, and pharmacology in schizophrenia. Am J Psychiatry (2003) 160(1):13-23. doi:10.1176/appi.ajp.160.1.13

82. Smeets F, Lataster T, Dominguez MD, Hommes J, Lieb R, Wittchen HU, et al. Evidence that onset of psychosis in the population reflects early hallucinatory experiences that through environmental risks and affective dysregulation become complicated by delusions. Schizophr Bull (2012) 38(3):531-42. doi:10.1093/schbul/sbq117

83. Creswell JD, Lam S, Stanton AL, Taylor SE, Bower JE, Sherman DK. Does self-affirmation, cognitive processing, or discovery of meaning explain cancer-related health benefits of expressive writing? Pers Soc Psychol Bull (2007) 33(2):238-50. doi:10.1177/0146167206294412

84. Ehlers A, Clark DM. Predictors of chronic posttraumatic stress disorder: trauma memories and appraisals. In: Rothbaum BO, editor. Pathological Anxiety: Emotional Processing in Etiology and Treatment, (pp. 39-55). New York, NY: Guilford Press (2006). p. 272.

85. Rachman S. Emotional processing, with special reference to post-traumatic stress disorder. Int Rev Psychiatry (2001) 13(3):164-71. doi:10.1080/ 09540260120074028

86. Berry K, Barrowclough C, Byrne J, Purandare N. Coping strategies and social support in old age psychosis. Soc Psychiatry Psychiatr Epidemiol (2006) 41(4):280-4. doi:10.1007/s00127-005-0023-1

87. Horan WP, Blanchard JJ. Neurocognitive, social, and emotional dysfunction in deficit syndrome schizophrenia. Schizophr Res (2003) 65(2):125-37. doi:10.1016/S0920-9964(02)00410-3

88. Morrison AP, Wells A. A comparison of metacognitions in patients with hallucinations, delusions, panic disorder, and non-patient controls. Behav Res Ther (2003) 41(2):251-6. doi:10.1016/S0005-7967(02)00095-5

89. Lysaker PH,Clements CA, WrightDE, Evans J, Marks KA. Neurocognitive correlates of helplessness, hopelessness, and well-being in schizophrenia. J Nerv Ment Dis (2001) 189(7):457-62. doi:10.1097/00005053-200107000-00007

90. Lysaker PH, Davis LW, Lightfoot J, Hunter N, Stasburger A. Association of neurocognition, anxiety, positive and negative symptoms with coping preference in schizophrenia spectrum disorders. Schizophr Res (2005) 80(2):163-71. doi:10.1016/j.schres.2005.07.005

91. Lysaker PH, Bryson GJ, Marks K, Greig TC, Bell MD. Coping style in schizophrenia: associations with neurocognitive deficits and personality. Schizophr Bull (2004) 30(1):113-21. doi:10.1093/oxfordjournals.schbul.a007056

92. Galdos M, Simons C, Fernandez-Rivas A, Wichers M, Peralta C, Lataster T, et al. Affectively salient meaning in random noise: a task sensitive to psychosis liability. Schizophr Bull (2011) 37(6):1179-86. doi:10.1093/schbul/sbq029

93. Morrison AP. The interpretation of intrusions in psychosis: an integrative cognitive approach to hallucinations and delusions. Behav Cogn Psychother (2001) 29(03):257-76. doi:10.1017/S1352465801003010

94. Juckel G, SchlagenhaufF, Koslowski M, Filonov D, Wüstenberg T, Villringer A, et al. Dysfunction of ventral striatal reward prediction in schizophrenic patients treated with typical, not atypical, neuroleptics. Psychopharmacology (2006) 187(2):222-8. doi:10.1007/s00213-006-0405-4

95. Simon JJ, Biller A, Walther S, Roesch-Ely D, Stippich C, Weisbrod M, et al. Neural correlates of reward processing in schizophrenia - relationship to apathy and depression. Schizophr Res (2010) 118(1):154-61. doi:10.1016/ j.schres.2009.11.007

96. Macdonald EM, Pica S, McDonald S, Hayes RL, Baglioni AJ Jr. Stress and coping in early psychosis: role of symptoms, self-efficacy, and social support in coping with stress. Br J Psychiatry (1998) 172:122-7.

97. Gard DE, Kring AM, Gard MG, Horan WP, Green MF. Anhedonia in schizophrenia: distinctions between anticipatory and consummatory pleasure. Schizophr Res (2007) 93(1):253-60. doi:10.1016/j.schres.2007.03.008

98. Foussias G, Agid O, Fervaha G, Remington G. Negative symptoms of schizophrenia: clinical features, relevance to real world functioning and specificity versus other CNS disorders. Eur Neuropsychopharmacol (2014) 24(5):693-709. doi:10.1016/j.euroneuro.2013.10.017

99. Horan WP, Ventura J, Mintz J, Kopelowicz A, Wirshing D, ChristianHerman J, et al. Stress and coping responses to a natural disaster in people with schizophrenia. Psychiatry Res (2007) 151(1):77-86. doi:10.1016/ j.psychres.2006.10.009

100. Phillips LJ, Francey SM, Edwards J, McMurray N. Strategies used by psychotic individuals to cope with life stress and symptoms of illness: a systematic review. Anxiety Stress Coping (2009) 22(4):371-410. doi:10.1080/1061580090 2811065

101. Jimeno Bulnes N, Jimeno Valdes A, Aragón ML, Fernández L. Psychopathological verbal expression of self-perceived stress in three groups of psychotic patients. Psychopathology (1997) 30(1):39-48. doi:10.1159/000285027

102. Ritsner M, Modai I, Ponizovsky A. Assessing psychological distress in psychiatric patients: validation of the Talbieh Brief Distress Inventory. Compr Psychiatry (2002) 43(3):229-34. doi:10.1159/000285027

Conflict of Interest Statement: The authors declare that the research was conducted in the absence of any commercial or financial relationships that could be construed as a potential conflict of interest.

The reviewer OM and handling Editor declared their shared affiliation, and the handling Editor states that the process nevertheless met the standards of a fair and objective review.

Copyright (๑) 2016 Mazor, Gelkopf, Mueser and Roe. This is an open-access article distributed under the terms of the Creative Commons Attribution License (CC BY). The use, distribution or reproduction in other forums is permitted, provided the original author(s) or licensor are credited and that the original publication in this journal is cited, in accordance with accepted academic practice. No use, distribution or reproduction is permitted which does not comply with these terms. 